\title{
Application of the Seven-Factor-Model of Personality to an Italian Preschool Sample
}

\author{
Maria Grazia Melegari', Margherita Innocenzi ${ }^{2}$, Assunta Marano ${ }^{3} 凶$, Loredana De Rosa ${ }^{4}$, \\ Renato Donfrancesco ${ }^{5}$, Sandor Rozsa ${ }^{6}$, and C. Robert Cloninger ${ }^{7}$
}

${ }^{1}$ Asl RM A Rome, Italy

${ }^{2}$ ASL RM B Rome, Italy

${ }^{3}$ Department of Life, Health and Environmental Sciences, University of L'Aquila, Coppito (AQ), Italy

${ }^{4}$ Private Cognitive Behavioral Psychotherapist, Rome, Italy

${ }^{5}$ Asl RM B, Sandro Pertini Hospital, Rome, Italy

${ }^{6}$ Center for Well Being, Washington University School of Medicine, St Louis, MO, USA

${ }^{7}$ Director, Center for Well Being, Washington University School of Medicine, St Louis, MO, USA

\begin{abstract}
Objective Advances in dimensional assessment of children in healthy and clinical populations has renewed interest in the study of temperament. Cloninger's Temperament and Character Inventory (TCI) has shown high reliability and internal consistency. Adult and adolescent versions have been translated into a number of languages and validated in cross-cultural studies worldwide. To date only one preschool-TCI-based study has been conducted in early infancy with teachers as observers. The present study is aimed to test an Italian Preschool version of the Temperament and Character Inventory (PsTCI). This is the first replication and the first validation study of TCI on preschoolers with parents as observers.
\end{abstract}

Methods 395 preschool children, recruited from pediatric communities and day-care centres throughout Italy, participated in the study. Parents of each child enrolled in the study and completed a PsTCI about the child. Standard psychometric tests of reliability and validation were performed.

Results Exploratory factor analyses demonstrated the presence of distinct domains for temperament and character. TCI dimensions had good internal consistency with Cronbach's alpha ranging values $(|0.60|-|0.81|)$. Gender differences were found for Harm Avoidance $(\beta=-0.186 ; p \leq 0.001)$ and Self-Directedness $(\beta=-0.216 ; \mathrm{p} \leq 0.01)$, and accounted for $5-35 \%$ of the observed variance.

Conclusion The present work suggests the psychological complexity of Cloninger's model and confirms its application in pre-school children from diverse environmental and cultural backgrounds. The results confirm that Cloninger's instrument for temperament and character evaluations can also be used with different observers and highlight the importance of considering cultural and demographic differences in the assessment of temperament and character in preschoolers.

Psychiatry Investig 2014;11(4):419-429

Key Words Temperament and Character Inventory, Preschoolers, Italian PsTCI.

\section{INTRODUCTION}

In recent years, significant advances in understanding the neurobiological and psychosocial causes of human behavior have enabled the creation of clinically useful models of per-

Received: July 29, 2013 Revised: October 19, 2013

Accepted: October 22, 2013 Available online: October 20, 2014

$\triangle$ Correspondence: Assunta Marano, $\mathrm{PhD}$

Departmant of Life, Health and Environmental Sciences, University of L'Aquila, Via Giovanni Falcone 25, 67100, Coppito (AQ), Italy

Tel: +39086243408 , Fax: +390862433425

E-mail: assunta.marano@univaq.it

(a) This is an Open Access article distributed under the terms of the Creative Commons Attribution Non-Commercial License (http://creativecommons.org/licenses/by$\mathrm{nc} / 3.0$ ) which permits unrestricted non-commercial use, distribution, and reproduction in any medium, provided the original work is properly cited. sonality development, such as the models of Cloninger, Zuckerman, and Eysenck. ${ }^{1-3}$ The most clinically useful and realistic studies on personality have been made using Cloninger's Temperament and Character Inventory (TCI). It allows assessment of the complex biopsychosocial processes that occur within an individual as a non-linear dynamical process. ${ }^{4-7}$ Cloninger's seven-dimensional psychobiological model has been developed and continually revised and updated and over the last 20 years. ${ }^{89}$ TCI measures both the emotional core of personality (i.e., temperament dimensions) and the higher cognitive processes that regulate conflicts among various emotional drives (i.e., character dimensions). ${ }^{10}$ Many clinicians and researchers have used the TCI as a tool in studies of personality in both normal and pathology-affected adult 
population samples. ${ }^{10,13}$

Much research has been conducted into child temperament in early infancy and in preschool age children, using different theorical models. ${ }^{17,18}$ Despite the heterogeneity of the different dimensional and theoretical approaches at present, there is consensus on a number of aspects: 1) temperament is characterized by moderate heritability, 2) temperament traits differentiating individuals are present at an early age, and 3) temperament traits are moderately stable throughout the lifespan of the person. ${ }^{19}$ Experiential evidence from clinical studies has established how early temperamental differences relate to early childhood behavioural problems, social relationship and cognition..$^{20}$ These follow-up studies have shown that early behavioural and temperamental differences already evident in children at 3-years of age are were consistent from toddlerhood to middle childhood. ${ }^{21}$ Researchers in infant and childhood temperament have shown that a toddler's 'difficult temperament', characterized by aggressive behaviour and other forms of disruptive conduct, are predictive of externalizing disorders at preschool age. ${ }^{22}$ In addition, temperament traits (emotionality and skyness) were associated with childhood anxiety disorders in population studies. ${ }^{23}$

Recently the scientific basis of Cloninger's personality construct is of interest to child psychiatrists because many researchers and clinicians regard the personality assessment of psychiatric patients in childhood as a critical and fundamental step. ${ }^{6,24,25}$

To these ends, two versions of the TCI have been set up for developmental age: the Junior Temperament Character Inventory (JTCI) and the Preschool Temperament Character Inventory (PsTCI), the former for children between the ages of six and seventeen and the later for preschool children between two and five years of age. The JTCI has been translated into a number of languages and validated in cross-cultural studies worldwide. ${ }^{29-31}$ In recent years research has been carried out using JTCI to identify specific temperamental and character profiles in children and adolescents with psychiatric disorders. ${ }^{29,32-34}$ For example, using the JTCI, children with Attention Deficit Hyperactivity Disorder (ADHD) and subthreshold ADHD have a profile of high novelty seeking, low persistence, and low self-directedness (SD), when compared with those of a control group. In addition, application of JTCI $^{29,35}$ has shown that children and adolescents with social phobias have a profile of high harm avoidance and low SD.

To date only one PsTCI-based study has been conducted on the seven-factor model application in early infancy. ${ }^{36}$ In this study, the seven-factor model was validated in 241 preschoolers enrolled from four high-quality day-care centres where primary day-caregivers completed the PsTCI. Exploratory and confirmatory factor analyses, showed high levels of internal consistency and inter-rater-reliability as well as a high degree of stability of interindividual differences in temperament and character over a 3-year period from toddlerhood to early school age in 29 preschoolers.

Comparison between PsTCI dimensions and temperament dimensions as measured using estabilished Colorado Child temperament inventory were performed, highlighted interesting relation between two instruments. ${ }^{36}$

The objectives of our study were to:

Replicate observations about temperament and character in a sample of Italian preschoolers, but in this case, with the parents as observers instead of teachers. As most research on temperament in early infancy and in preschool children was conducted with parents as observers this will allow us to compare our results with those of other studies on temperament.

This paper represents the first study to examine, the psychometric proprieties of PsTCI version in a different country from that original one and to obtain specific normative data for the Italian preschool population.

\section{TCI model in preschoolers}

TCI deconstructs personality into seven dimensions: four of temperament and three of character. Temperament dimensions refer to individual differences in the strength of drives underlying basic emotions, which are moderately stable throughout a person's life. Each temperament-related dimension is influenced by neuromodulatory factors and represents a specific response to stimuli. Temperament was described in terms of four heritable dimensions: Harm Avoidance (HA), Novelty Seeking (NS), Reward Dependence (RD) and Persistence $(\mathrm{P})$. HA represents the tendency to respond intensely to adversity stimuli with inhibitory behaviours to avoid punishment, novelties and frustrating non-rewards. NS represents the tendency to respond with exhilaration and excitement to novel stimuli or cues for potential rewards, which leads to frequent exploratory activities in pursuing potential rewards as well as active avoidance of monotony. RD represents the tendency to intensely respond to signals of reward - in particular verbal signals of social approval. Persistence $(\mathrm{P})$ represents a tendency to maintain or resist the extinction of behaviours that have previously been associated with rewards or relief from punishment. Differences in average values correspond to specific emotional and behavioural dispositions (i.e., anxiety, anger, impulsivity, social detachment). Extensive data indicate that individual differences in personality are causal antecedents contributing to the full range of psychopathology. ${ }^{6,13}$

The character dimensions were developed to measure additional aspects of personality that allow people to be valued for their skill in regulating emotion and impulsivity regardless of temperament. They provide information about a person's 
goals, values, and object relationships, distinguishing a person's self-directedness (SD), cooperativeness (CO), and awareness of their participation in things greater than their individual self (Self-transcendence, ST). Temperamental and character dimensions constitute different personality configurations. Personality traits vary quantitatively and occur in all possible combinations and define the wide variety of personality in the general as well as in the clinical population..$^{39,40}$

\section{METHODS}

\section{Sample and procedure}

The PsTCI was completed by the parents of 400 3-6-yearold children ( 3 year-old children $\mathrm{n}=58 ; 4$ year-old children, $\mathrm{n}=147 ; 5$ year-old children, $\mathrm{n}=117 ; 6$ year-old children, $\mathrm{n}=73$ ). One child was excluded from the analysis due to excessive missing data ( $\geq 10 \%$ ). The sample was made up of 196 boys and 199 girls (four cases from central Italy we have no information about gender). The mean age of the sample was 53.64 months ( $\mathrm{SD}=11.38)$. The detailed demographic characteristics of the sample are shown in Table 1. Children were recruited from kindergartens or community paediatric medical practices located in different geographical areas of Italy (North, Centre, and South). Overall there were 305 from central Italy (Latium), 53 from southern regions (Apulia and Campania) and 37 from northern Italy (Lombardy). A retest was performed after two weeks on a random sub-sample of 45 children. The validation study of the Italian version of Preschooler Temperament and Character Inventory (PsTCI) considered different methodological procedural steps in order to maximize reliability. We followed the Guidelines for the Process of Cross-Cultural Adaptation of Self Report Measures for the Translation of instrument. ${ }^{41,42}$ The first step was the translation into Italian of the original (US English) PsTCI version of the questionnaire carried out by independently by two experts in American English language and a 'reconciled version' of the questionnaire was produced. The 'reconciled version' was then back translated by two native-language translators who were unfamiliar with the original version of the questionnaire. Minor changes were required in the Italian version to make it more understandable to parents, care-givers and teachers who would be required to complete the question- naire. These changes were made with the supervision and approval of Professor Cloninger. Finally, the project was sent to a number of paediatricians, parents and teachers from the above-mentioned Italian regions for them to be involved in the study planning as well to gain an understanding of the recruitment procedures. During ad hoc meetings, participants in the project received outlines of the questionnaire, the rating scale as well as detailed instructions on how to complete it. At the same time permission was obtained from parents for their children to participate in the study.

Parents of all children enrolled in the study completed a PsTCI. For kindergartens only the project also allowed for the compilation of a further Italian Temperament Questionnaire ${ }^{43}$ by parents (for concurrent validity evaluation purposes) and of the PsTCI by teachers (to check inter-rater reliability values). To test the stability level of the seven factors, research project also scheduled a follow-up assessment 2 years later.

\section{Measure}

The PsTCI is a questionnaire composed of 74 questions to measure seven dimensions of temperament and character. ${ }^{36}$ The questions were adaptable to preschool age children; in particular, ST was focused on capacity for pretense (make-believe) in play activities. Questions regarding each dimension were designed to be appropriate for preschool children and unambiguous for their parents to answer. Each dimension of the PsTCI structure is measured by a separate set of questions that also varied in number. For each item, the parents rated the children's temperament and character traits on a 5 point Likert scale: $1=$ definitely false; $2=$ mostly or probably false; $3=$ neither true nor false or about equally true and false; $4=$ mostly or probably true; $5=$ definitely true.

To assess concurrent validity we used Temperament Italian Questionnaires (QUIT) version for children aged 3 to 6 years. This questionnaire is validated on Italian sample (Axia G., Questionari Italiani per il Temperamento, 2002). The version for children aged 3 to 6 years is structured in 60 items on likert scal (1 "almost never" to 6 "almost always") describing child behaviour in three different contexts (child with the others; child on his play time; child facing of novelty or while $\mathrm{s} /$ he is performing an activity or a task). The scale of questionnaire are the following: Motor Control Activity (vigour of

Table 1. Demographic characteristics of the sample $(\mathrm{N}=395)$

\begin{tabular}{ccccc}
\hline \multirow{2}{*}{ Gender } & \multicolumn{3}{c}{ Region } & South \\
\cline { 2 - 4 } & North & Center & $29(54.7 \%)$ & $196(49.6 \%)$ \\
Boys & $20(54.1 \%)$ & $147(48.2 \%)$ & $24(45.3 \%)$ & $199(50.4 \%)$ \\
Girls & $17(45.9 \%)$ & $158(51.8 \%)$ & $53(100 \%)$ & $395(100 \%)$ \\
Total & $37(100 \%)$ & $305(100 \%)$ & & \\
\hline
\end{tabular}


movement and modulation of motor control activity); Attention (orientation, regulation and attention persistency); Inhibition to novelty (emotional reactivity introducing an adjustment to social context); Social Orientation (emotional answers in front of unknown people and attention/interest towards social stimuli); Positive Emotionality and Negative Emotionality (predominance of negative and positive emotions).

\section{Statistical analyses}

Means, standard deviations and Cronbach's alpha coefficients were calculated for each of the PsTCI scales. Test-retest reliabilities were assessed using by Pearson's correlation coefficients. Concurrent validity Gender differences were examined with t-test. Effect sizes (Cohen's d) were estimated from t-tests. Pearson's correlation coefficient was used to assess the linear association between 7 dimensions of the PsTCI.

Firstly, maximum likelihood confirmatory factor analyses (CFA) were conducted over the covariance matrices of the PsTCI temperament and character scales to test the hypothesized factor structures. The analyses were performed through the AMOS 7 statistical package. ${ }^{44}$ The following goodness-offit indices were used to assess the degree of fit between the proposed model and the sample data: 1 ) the $\chi^{2}$ statistic; 2 ) the comparative fit index (CFI); 3 ) the root mean square error of approximation (RMSEA); 4) the standardized root-meansquare residual (SRMR). CFI value greater than 0.90 suggest an acceptable fit. ${ }^{45,46}$ For the RMSEA, a cut-off value ranging from 0.05 or lower indicates good model fit and values up to 0.08 represent moderate model fit. An SRMR of between 0 and 0.05 indicates a good fit, and between 0.05 and 0.10 , an acceptable fit. ${ }^{47,48}$ Secondly, the factor structure was analyzed through a Principal Component Analysis (PCA) with Promax rotation. Temperament and character subscales were factor analyzed separately because the relationships among the temperament and character dimensions are strongly nonlinear that cannot be adequately specified by the linear assumptions of factor analysis ${ }^{7,8}$ (Cloninger, 2000, 2008).

Finally, these factor structures were compared with the original version of the PsTCI, that was validated with 305 children. Orthogonal Procrustes rotations $s^{49,50}$ and congruence coefficients between the factorial matrices are provided to demonstrate the equivalence between the American and Italian version of the PsTCI. A congruence coefficient of 0.90 or higher has been traditionally considered evidence of factor replication. ${ }^{51}$

Basic statistical analyses were carried out with version 19.0 of the SPSS statistical software, significance was assumed with $\mathrm{p}<0.05$.

\section{RESULTS}

\section{Exploratory factor analysis for temperament}

Exploratory factor analyses (principal components analysis with varimax rotation) were conducted separately for temperament and character as recommended by Cloninger. ${ }^{8}$ By examining both Kaiser criterion and Scree test method the four-factor solution was chosen, because it is the one with the cleanest factorial structure and represents the most parsimonious model. ${ }^{52,53}$ Other factorial solutions were omitted, such as those with nine (50\% observed variance), eight ( $47 \%$ observed variance), seven ( $44 \%$ observed variance), six ( $41 \%$ observed variance), and five (37\% observed variance) factors respectively, as in these cases the factors presented less than three items and did not produce interpretable results.

However, the exploratory factor analysis was reiterated for four factors (33.6\% observed variance) and it showed a content of empirically-derived factors reflecting four domains of temperament, in accordance with Cloninger's theoretical framework assumptions. ${ }^{54-56}$

The first extracted factor explained $13.6 \%$ of the total variance and comprised items reflecting the degree at which individual subjects easily fatigue, as well as the excessive worry and shyness. Factor 1 was defined by all of the HA items and two RD items (21. Child is something of a loner; 68. Child finds people more stimulating than anything else.) and one NS item (41. When upset by an unexpected situation, child quickly calms down).

The Factor 2 (8.1\%) was mainly defined by eight of the nine NS items, and two PS items (27. Child goes from toy to toy quickly; 7. Child plays with a single toy for long periods of time).

The third extracted factor explained $6.5 \%$ of the total variance and comprised items representing the hard-working and perseverance degree that individual subjects can achieve. This factor was defined by nine of the eleven PS items, and one RD item (70. Child stops fussing whenever he/she is talked to or picked up by someone).

The fourth extracted factor explained $5.3 \%$ of the total variance and included items reflecting the extent at which individuals are characterized by enhanced learning abilities while in presence of reward signals, which was defined seven of the ten $\mathrm{RD}$ items.

\section{Exploratory factor analysis for character}

An analysis of principal components was also conducted to define the appropriate pool of items to be designated as character assessment factors. After extraction, the item-loading tables were compared and it the number of factors to retain for rotation was decided. For the number selection of factors 
Table 2. Orthogonal procrustes rotated structure with congruence coefficients for PsTCI temperament items

\begin{tabular}{|c|c|c|c|c|c|}
\hline Temperament items & Factor 1 (HA) & Factor 2 (PS) & Factor 3 (NS) & Factor $4(\mathrm{RD})$ & Item congruence \\
\hline \multicolumn{6}{|l|}{ Harm avoidance } \\
\hline Q2 & 0.55 & -0.09 & 0.25 & -0.12 & $1.00^{* *}$ \\
\hline Q3 & -0.14 & 0.11 & 0.06 & 0.10 & 0.42 \\
\hline Q14 & -0.58 & 0.01 & 0.01 & -0.34 & $0.98^{* *}$ \\
\hline Q19 & -0.59 & 0.18 & -0.13 & 0.01 & $0.97^{* *}$ \\
\hline Q30 & 0.69 & 0.21 & -0.05 & 0.04 & $0.91^{*}$ \\
\hline Q31 & 0.53 & 0.12 & 0.13 & -0.09 & 0.86 \\
\hline Q33 & -0.47 & 0.14 & 0.23 & 0.03 & $1.00^{* *}$ \\
\hline Q46 & 0.52 & -0.12 & 0.34 & -0.21 & $0.96^{* *}$ \\
\hline Q58 & 0.64 & 0.16 & 0.05 & 0.10 & $0.95^{* *}$ \\
\hline Q60 & 0.58 & -0.05 & 0.29 & 0.12 & 0.86 \\
\hline \multicolumn{6}{|l|}{ Novelty seeking } \\
\hline Q11 & 0.05 & -0.00 & 0.63 & 0.29 & $0.98^{* *}$ \\
\hline Q12 & -0.13 & 0.06 & 0.53 & -0.15 & $0.92^{*}$ \\
\hline Q20 & -0.12 & -0.05 & 0.59 & 0.27 & 0.69 \\
\hline Q22 & -0.07 & -0.11 & 0.61 & 0.23 & $0.98^{* *}$ \\
\hline Q24 & 0.17 & 0.01 & 0.61 & 0.16 & $0.98^{* *}$ \\
\hline Q26 & -0.15 & 0.11 & -0.39 & -0.09 & $0.97^{* *}$ \\
\hline Q39 & -0.08 & -0.39 & 0.53 & -0.07 & $0.88^{*}$ \\
\hline Q41 & -0.38 & 0.18 & -0.13 & -0.05 & $0.87^{*}$ \\
\hline Q57 & -0.17 & 0.25 & -0.29 & 0.10 & 0.82 \\
\hline \multicolumn{6}{|l|}{ Reward dependence } \\
\hline Q4 & 0.10 & -0.11 & 0.14 & 0.51 & $0.99^{* *}$ \\
\hline Q9 & -0.38 & 0.07 & -0.02 & -0.50 & $0.99^{* *}$ \\
\hline Q21 & 0.46 & 0.08 & 0.19 & 0.34 & $0.89 *$ \\
\hline Q35 & -0.31 & -0.02 & 0.15 & -0.26 & $0.96^{* *}$ \\
\hline Q55 & 0.03 & 0.15 & 0.20 & -0.54 & 0.84 \\
\hline Q67 & 0.19 & -0.05 & 0.16 & 0.50 & $0.97^{* *}$ \\
\hline Q68 & -0.43 & 0.03 & 0.18 & -0.09 & 0.80 \\
\hline Q70 & -0.05 & 0.11 & -0.07 & -0.09 & 0.67 \\
\hline Q72 & 0.07 & -0.07 & 0.16 & 0.52 & $0.98^{* *}$ \\
\hline Q74 & 0.03 & -0.01 & 0.02 & 0.62 & $0.97^{* *}$ \\
\hline \multicolumn{6}{|l|}{ Persistence } \\
\hline Q5 & 0.30 & -0.52 & 0.27 & 0.01 & $0.92 *$ \\
\hline Q6 & -0.17 & 0.53 & -0.08 & -0.00 & $0.99^{* *}$ \\
\hline Q7 & 0.17 & 0.18 & -0.17 & -0.08 & $0.88^{*}$ \\
\hline Q16 & 0.04 & 0.56 & -0.03 & -0.19 & $0.95^{* *}$ \\
\hline Q17 & 0.35 & -0.46 & 0.24 & -0.03 & $0.99^{* *}$ \\
\hline Q18 & -0.22 & 0.61 & -0.11 & -0.10 & $0.87^{*}$ \\
\hline Q27 & -0.15 & -0.15 & 0.30 & 0.07 & 0.84 \\
\hline Q47 & 0.10 & 0.38 & 0.30 & -0.24 & 0.76 \\
\hline Q52 & 0.09 & 0.63 & 0.23 & 0.05 & $0.94^{* *}$ \\
\hline Q64 & -0.02 & 0.69 & 0.15 & -0.05 & $0.95^{* *}$ \\
\hline
\end{tabular}


Table 2. Continued

\begin{tabular}{cccccc}
\hline Temperament items & Factor 1 (HA) & Factor 2 (PS) & Factor 3 (NS) & Factor 4 (RD) & Item congruence \\
\hline Q65 & -0.04 & -0.47 & 0.28 & 0.06 & $0.95^{* *}$ \\
Factor congruence & $0.95^{* *}$ & $0.91^{* *}$ & $0.88^{*}$ & $0.86^{*}$ & $0.90^{* *}$ \\
\hline
\end{tabular}

Loadings with absolute values of 0.40 or more are shown in bold. Theoretically expected loadings have a grey background. ${ }^{*}$ congruence higher than that of $95 \%$ of rotations from random data, ${ }^{* *}$ congruence higher than that of $99 \%$ of rotations from random data. NS: Novelty Seeking, HA: Harm Avoidance, RD: Reward Dependence, PS: Persistence, PsTCI : Preschool version of Temperament and Character Inventory

to retain, both Kaiser criterion and Scree test method were applied..$^{52}$ By examining the eigen values' graph, it was observed that, in this case, the number of data points above the break was seven. The three-factor solution was chosen because it is the one with the cleanest factorial structures and represents the most parsimonious model. ${ }^{53}$

Other factorial solutions were omitted such as those with seven ( $43 \%$ observed variance), six ( $40 \%$ observed variance) and five (36\% observed variance) factors respectively, as in these cases the factors presented less than three items and did not produce interpretable results. The exploratory factor analysis was reiterated for three factors (31.5\% observed variance) and showed a content of empirically-derived factors reflecting three domains of character in accordance with Cloninger's theoretical framework assumptions.

The first extracted factor explained $17.9 \%$ of the total variance and comprised fourteen of the sixteen $\mathrm{CO}$ items reflecting individual relational abilities towards the others and how they evolve in time as a function of social learning and maturation of the interpersonal behaviour and was cooperativeness.

The second extracted factor explained $7.7 \%$ of the total variance and entails items representing concepts about self of individual subjects were evaluated and thus it was referred to as $\mathrm{SD}$, which was defined by eight of the ten $\mathrm{SD}$ items.

The third extracted factor explained $5.7 \%$ of the total variance and included items reflecting the extent at which the individuals are characterized by transpersonal relational abilities which was defined by all of the ST items and two SD (43. Child really likes to be a helper; 28 . When a child has unmet needs he/she actively seeks help from a caregiver, rather than just getting upset) and two CO items (69. Child seems to be considerate of others; 38 . Child likes to share with other children).

\section{Confirmatory factor analyses for temperament and character}

The confirmatory factor analyses (CFA) were conducted separately from the pool of items designated to assess temperament as well as those designated to assess character. As several researchers ${ }^{44,48,57}$ suggest the adequacy level of the model has been estimated on the basis of various indices of fit: chi square, root mean square error of approximation (RMSEA, a value less than 0.06 is considered a good fit), the standardized root mean square residual (SRMR, a value less than 0.08 is considered a good fit), and comparative fit index (CFI, a value on average .9 is considered a good fit).

Confirmatory factor analysis results for temperament indicated a poor fit in relation to the hypothesized four-factor model of temperament: $\chi^{2}=2002.53, \mathrm{Df}=734, \mathrm{p}<0.0001$; RM$\mathrm{SEA}=0.066, \mathrm{SRMR}=0.082, \mathrm{CFI}=0.611$.

Confirmatory factor analysis of character items indicated that the hypothesized three-factor model of PsTCI provided a poor fit for the data $\left(\chi^{2}=1226.28, \mathrm{Df}=524, \mathrm{p}<0.0001\right.$; RMSEA $=$ $0.058, \mathrm{SRMR}=0.073, \mathrm{CFI}=0.730$ ).

\section{Congruence and procrustes-rotated structure}

To examine the cross-cultural replicability of the PsTCI factor structure, orthogonal Procrustes rotation were used. Table 2 and 3 present the Procrustes-rotated factor structure in the Italian sample.

Most of the temperament items has its highest loading on the intended factor, except item 41 (NS), 21 (RD), 35 (RD), 68 (RD), 70 (RD), and 27 (PS). Out of the 40 items, 22 items showed a significant congruence coefficient at $\mathrm{p}<0.01$, and another 8 items at $\mathrm{p}<0.05$. The remanining 10 items ( $2 \mathrm{NS}$ items, $3 \mathrm{HA}$ items, $3 \mathrm{RD}$ items, 2 PS items) differed from the American normative sample matrix.

Only 4 items from the total 34 character items have highest loading on an unexpected factors: item 28 (SD), item 43 (SD), item 38 (CO), and 69 (SD). Out of all character items, 23 items showed a significant congruence coefficient at $\mathrm{p}<0.01$, and another 7 items at $\mathrm{p}<0.05$. Four items ( $1 \mathrm{SD}$ item, $3 \mathrm{CO}$ items) differed from the American normative sample matrix.

\section{Concurrent validity, reliability and gender differences}

We estimated the coefficients of internal consistencies (Cronbach's alpha), the coefficients of stability (test-retest Pearson correlation), and sex differences for each dimension of both temperament and character domains. Cronbach's alpha relating to the PsTCI questionnaire is shown in Table 4, the alphas were between 0.60 and 0.81 . The dimension of cooperativeness showed the highest internal consistency $(0.81)$ 
whereas the dimension of reward dependence represented the case with the lowest internal consistency (0.60). As second reliability method, the test-retest reliability procedure to as- sess the consistency of a measurement between two different times (range 15 days) on a sub-sample of 45 children recruited from four randomly-selected classrooms. The high corre-

Table 3. Orthogonal Procrustes rotated structure with congruence coefficients for PsTCl character items

\begin{tabular}{|c|c|c|c|c|}
\hline Character items & Factor $1(\mathrm{CO})$ & Factor 2 (SD) & Factor 3 (ST) & Item congruence \\
\hline \multicolumn{5}{|l|}{ Self-directedness } \\
\hline Q13 & -0.14 & -0.51 & 0.19 & $0.95^{* *}$ \\
\hline Q23 & 0.11 & 0.53 & -0.12 & $1.00 * *$ \\
\hline Q28 & -0.11 & -0.14 & 0.36 & 0.66 \\
\hline Q29 & 0.12 & 0.70 & 0.03 & $1.00^{* *}$ \\
\hline Q36 & 0.00 & -0.72 & 0.07 & $0.98^{* *}$ \\
\hline Q37 & 0.00 & -0.44 & 0.39 & $0.98^{* *}$ \\
\hline Q40 & 0.33 & 0.36 & 0.15 & $0.95^{* *}$ \\
\hline Q42 & 0.23 & 0.62 & 0.02 & $1.00^{* *}$ \\
\hline Q43 & -0.22 & -0.21 & 0.37 & $0.94^{*}$ \\
\hline Q51 & 0.23 & 0.30 & -0.05 & $0.88^{*}$ \\
\hline \multicolumn{5}{|l|}{ Cooperativeness } \\
\hline Q1 & 0.60 & 0.03 & 0.00 & $1.00^{* *}$ \\
\hline Q8 & -0.45 & 0.00 & 0.24 & $0.92 *$ \\
\hline Q10 & 0.29 & -0.21 & 0.02 & 0.82 \\
\hline Q25 & 0.55 & 0.09 & -0.18 & $0.99^{* *}$ \\
\hline Q32 & 0.40 & 0.24 & -0.17 & 0.79 \\
\hline Q34 & -0.34 & -0.25 & 0.03 & $0.99^{* *}$ \\
\hline Q38 & -0.24 & -0.30 & 0.29 & $0.92 *$ \\
\hline Q44 & 0.35 & 0.27 & -0.04 & $0.95^{* *}$ \\
\hline Q49 & 0.72 & 0.09 & 0.00 & $0.97^{* *}$ \\
\hline Q54 & -0.45 & -0.12 & 0.13 & $0.93^{*}$ \\
\hline Q56 & 0.55 & 0.32 & -0.15 & $0.94^{*}$ \\
\hline Q59 & 0.50 & 0.20 & -0.03 & $1.00^{* *}$ \\
\hline Q61 & 0.69 & -0.00 & 0.05 & $0.97^{* *}$ \\
\hline Q62 & 0.66 & 0.20 & 0.07 & $0.99^{* *}$ \\
\hline Q63 & 0.58 & 0.08 & 0.14 & $0.97^{* *}$ \\
\hline Q69 & -0.18 & -0.31 & 0.33 & 0.65 \\
\hline \multicolumn{5}{|l|}{ Self-transcendence } \\
\hline Q15 & -0.06 & -0.05 & 0.39 & $0.86^{*}$ \\
\hline Q45 & -0.08 & -0.20 & 0.27 & $0.98^{* *}$ \\
\hline Q48 & 0.04 & 0.12 & 0.58 & $0.98^{* *}$ \\
\hline Q66 & 0.06 & 0.04 & 0.55 & $0.98^{* *}$ \\
\hline Q71 & -0.12 & -0.29 & 0.48 & $0.97^{* *}$ \\
\hline Q73 & -0.17 & -0.12 & 0.61 & $1.00^{* *}$ \\
\hline Q50 & -0.13 & 0.03 & 0.60 & $0.96^{* *}$ \\
\hline Q53 & -0.19 & 0.01 & 0.61 & $0.97^{* *}$ \\
\hline Factor Congruence & $0.94^{* *}$ & $0.93 * *$ & $0.93^{* *}$ & $0.93^{* *}$ \\
\hline
\end{tabular}

Loadings with absolute values of 0.40 or more are shown in bold. Theoretically expected loadings have a grey background. * congruence higher than that of $95 \%$ of rotations from random data, ${ }^{* *}$ congruence higher than that of $99 \%$ of rotations from random data. SD: Self-Directedness, CO: Cooperativeness, ST: Self-Transcendence, PsTCI: Preschool version of Temperament and Character Inventory 
lation between these measures showed a high test-retest stability of the scales: Pearson's correlation coefficients are varied from 0.73 to $0.98(\mathrm{p}<0.001)$.

The correlation matrices for the 4 temperament and 3 character dimensions and age are shown in Table 5. The highest correlations were for $\mathrm{CO}$ with NS (-0.72), and moderate correlations were obtained for SD with CO (0.49), and HA $(-0.46)$. All other correlation coefficients showed weaker $(\leq 0.40)$ relationships. Age correlated negatively with NS $(-0.26)$ and positively with PS (-0.16), CO (0.25) and ST (0.13).

In conclusion, concurrent validity was evaluated by comparing PsTCI domains with relevant domains in the QUIT questionnaire using Pearson's Correlation Coefficient (r). We found interested statistical significat correlation between all measures PsTCI temperament and character dimensions (except P) and QUIT. By correlation analysis we observed that the Temperamental configuration are mostly associated with predominance of negative and positive emotions especially in front of unknown people and attention/interest towards social stimuli [Harm Avoidance (HA) correlates significantly with Inhibition to novelty $(r=0.445 ; \mathrm{p}<0.001)$; Negative Emotionality $(\mathrm{r}=0.338 ; \mathrm{p}<0.05)$; Positive Emotionality $(\mathrm{r}=-0.170$; $\mathrm{p}<0.001$ ); Novelty Seeking (NS) correlates significantly with Negative Emotionality $(r=0.236$; $<<0.001)$; Reward Depen- dence $(\mathrm{RD})$ correlates significantly with Social Orientation $(\mathrm{r}=0.176 ; \mathrm{p}<0.001)$; Inhibition to novelty $(\mathrm{r}=-0.155 ; \mathrm{p}<0.05)$; Negative Emotionality $(r=-198 ; \mathrm{p}<0.001)$; Positive Emotionality $(\mathrm{r}=-0.146 ; \mathrm{p}<0.05)$; Persistence $(\mathrm{P})$ correlates significantly with Attention $(r=-359 ; \mathrm{p}<0.005)]$.

While, the Character dimensions are mostly associated with a component of attention as orientation, regulation and attention persistency (Self-directedness (SD), correlates significantly with Inhibition to novelty $(r=-0.215 ; \mathrm{p}<0.001)$; Negative Emotionality $(r=-0.259 ; \mathrm{p}<0.001)$; Attention $(\mathrm{r}=-0.146$; $\mathrm{p}<$ 0.05).; Cooperativeness (CO), correlates significantly with Social Orientation $(r=0.176 ; \mathrm{p}<0.005)$; Negative Emotionality $(\mathrm{r}=-0.134 ; \mathrm{p}<0.001)$; Attention $(\mathrm{r}=-0.162 ; \mathrm{p}<0.05)$. Self-transcendence (ST) correlates significantly with Negative Emotionality $(\mathrm{r}=0.161 ; \mathrm{p}<0.05)$; Attention $(\mathrm{r}=-0.184 ; \mathrm{p}<0.05)$.

\section{DISCUSSION}

The present study is aimed to test an Italian Preschool version of the Temperament and Character Inventory (PsTCI). The italian study is the first replication and the first validation of TCI on preschoolers with parents as observers. The methodology of validation is articulated in different aspetcs of validation (structural validaton exploratory and confirmatory)

Table 4. Internal consistency reliabilities $(\alpha)$, test-retest correlations (Pearson $r$ ), means, standard deviations (SD), and gender differences on the PsTCl dimensions

\begin{tabular}{|c|c|c|c|c|c|c|c|c|c|c|}
\hline \multirow{2}{*}{ PsTCI dimensions } & \multirow{2}{*}{$\begin{array}{c}\text { Number of } \\
\text { item }\end{array}$} & \multirow{2}{*}{ Cronbach's $\alpha$} & \multirow{2}{*}{ Test-retest $\mathrm{r}$} & \multicolumn{2}{|c|}{ Girls } & \multicolumn{2}{|c|}{ Boys } & \multirow{2}{*}{$\mathrm{t}$} & \multirow{2}{*}{$\mathrm{p}$ value } & \multirow{2}{*}{ Cohen's d } \\
\hline & & & & Mean & SD & Mean & $\mathrm{SD}$ & & & \\
\hline Novelty seeking (NS) & 9 & 0.71 & 0.77 & 2.50 & 0.65 & 2.62 & 0.66 & 1.90 & 0.058 & 0.183 \\
\hline Harm avoidance (HA) & 10 & 0.76 & 0.95 & 2.47 & 0.66 & 2.60 & 0.67 & 1.91 & 0.056 & 0.195 \\
\hline Reward dependence (RD) & 10 & 0.60 & 0.98 & 4.16 & 0.47 & 3.98 & 0.45 & 3.65 & $<0.001$ & 0.391 \\
\hline Persistence (PS) & 11 & 0.70 & 0.96 & 3.41 & 0.57 & 3.30 & 0.58 & 1.90 & 0.058 & 0.191 \\
\hline Self-directedness (SD) & 10 & 0.71 & 0.97 & 4.10 & 0.52 & 3.94 & 0.54 & 2.88 & 0.004 & 0.301 \\
\hline Cooperativeness (CO) & 16 & 0.81 & 0.96 & 3.87 & 0.52 & 3.62 & 0.57 & 4.41 & $<0.001$ & 0.458 \\
\hline Self-Transcendence (ST) & 8 & 0.67 & 0.73 & 3.92 & 0.58 & 3.72 & 0.65 & 3.18 & 0.002 & 0.324 \\
\hline
\end{tabular}

PsTCI: Preschool version of Temperament and Character Inventory

Table 5. Correlations between temperament and character scales and age $(\mathrm{N}=399)$

\begin{tabular}{|c|c|c|c|c|c|c|c|}
\hline & NS & HA & $\mathrm{RD}$ & PS & $\mathrm{SD}$ & $\mathrm{CO}$ & ST \\
\hline Novelty seeking (NS) & - & & & & & & \\
\hline Harm avoidance (HA) & $0.19^{* *}$ & & & & & & \\
\hline Reward dependence (RD) & $-0.22^{* *}$ & $-0.36^{* *}$ & & & & & \\
\hline Persistence (PS) & $-0.28^{* *}$ & $-0.14^{* *}$ & $0.21^{* *}$ & & & & \\
\hline Self-directedness (SD) & $-0.39^{* *}$ & $-0.46^{* *}$ & $0.42^{* *}$ & $0.39^{* *}$ & & & \\
\hline Cooperativeness (CO) & $-0.72^{* *}$ & $-0.21^{* *}$ & $0.39^{* *}$ & $0.36^{* *}$ & $0.49^{* *}$ & & \\
\hline Self-transcendence (ST) & $-0.13^{* *}$ & $-0.10^{*}$ & $0.28^{* *}$ & $0.40^{* *}$ & $0.31^{* *}$ & $0.25^{* *}$ & \\
\hline Age & $-0.26^{* *}$ & 0.00 & 0.06 & $0.21^{* *}$ & 0.05 & $0.25^{* *}$ & $0.13^{* *}$ \\
\hline
\end{tabular}


and reliability (internal consistency, test-retest stability and concurrent reliability).

The sample, composed of 399 children from different Italian regions, was not completely representative but, was however large enough to elaborate large and different enough to provide approximate norms for a general population. The results confirm that Cloninger's instrument for temperament and character evaluations can be adapted to preschoolers with different environmental and cultural background, and can also be used with different observers. Structural analysis (exploratory and confirmatory factor factor analyses) also demonstrated that the PsTCI is an effective tool to identify distinct domains of temperament and character in accordance to Cloninger's model..$^{29}$ The stability value estimated for each domain is reasonably acceptable (Pearson's correlation coefficients are varied from 0.73 to $0.98, \mathrm{p}<0.001)$ and the correlation between the subscales was strong. Internal consistency of the seven dimensions were high (Cronbach's alphas are varied from 0.60 to 0.81 ), only with the exception of one scale (RD, Cronbach's alpha: 0.60), in accordance with the results of the PsTCI application to American sample. Confirmatory factor analyses showed a poor degree of fit between the loading of empirically-derived factors and the designation of theoretically-derived items (with regard to temperament: $\chi^{2}=2002.53$, $\mathrm{Df}=734, \mathrm{p}<0.0001$; RMSEA $=0.066$, SRMR $=0.082$, CFI $=0.611$ and regard to character: $\chi^{2}=1226.28, \mathrm{Df}=524, \mathrm{p}<0.0001$; RM$\mathrm{SEA}=0.058, \mathrm{SRMR}=0.073, \mathrm{CFI}=0.730$ ). However, the exploratory factor analysis and orthogonal Procrustes rotation supported the expected structures, and the Italian version of PsTCI replicates the American normative factor structure.

The congruence coefficients for the 7 dimensions ranged from 0.86 to 0.95 , and most of the items clearly define the intended factor of predetermined empirical structure and this can be interpreted as replication of the original result.

"We used Temperament Italian Questionnaires (QUIT) to test concurrent validity. This instrument explore six dimension of temperament: three areas are connected to the child adjustment to the environment (the Motor activity, the Attention and the Inhibition to novelty areas) and the other three areas are related to the child adaptation to the social world (Social orientation, Positive emotionality and Negative Emotionality areas). The concurrent validity analisys highlighted a strong relation between all PsTCI dimentions and Temperament measures of QUIT. In particular all PsTCI temperament and character dimensions (except Persistence) showed a significant relation with negative emotionality of the QUIT. More, character PsTCI dimensions were strongly related also with attention QUIT. A significant relation was found between two temperament PsTCI dimensions (HA and RD) and novelty inhibition and between $\mathrm{RD}$ and orientamento sociale, activity of QUIT. Sintetically, all PsTCI dimension are significantly correlated with well established Temperament dimensions of QUIT; particularly negative emotionality, attention and novelty inhibition".

Regional influences, due to the different geographical regions the children came from, were not study subjects as the sampling distribution was not uniform. The scientific literature is inconsistent as to how gender affects temperament and adjustment, but our study also included statistical analyses on gender differences as there is some experimental evidence on this subject. Meta-analyses on gender differences related to some aspects of temperament reported by Else-Quest et al. ${ }^{58}$ showed that the level of control is higher in girls whereas levels of surgency are higher in boys. Furthermore, Werner ${ }^{59}$ found that temperament can predict the resilience capability in girls only, whereas Eisenberg et al. ${ }^{60}$ found that the low negative emotionality was protective in the development of poor social skills in boys only. In our sample of the study the gender variable presents significant differences as to four dimensions (RD, SD, CO, and ST) but not in three temperament dimensions: Novelty seeking, Harm avoidance and Persistence.

The clinical aspect is the limitation and the implication of this study: the authors suggest the expressiveness of different temperament traits and character in different psychopathological manifestations. Starting from this intuition, the authors believe that the traits in the population tested with the pTCI pathological profiles delineate different temperament and character. The implications regarding the clinical use of the pTCI: the clinician could use the pTCI to probe the vulnerability to disease or the severity of the disease. The authors hypothesized methods analysis and evaluation articulated in order to demonstrate the structure of temperament and chacter traits in pathological profiles. The importance of this implication is very clear in a preschool sample tipical or atypical.

\section{CONCLUSION}

The present work suggests the psychological complexity of Cloninger's model, confirms its application in early age and highlights the importance of considering cultural and demographic differences in the assessment of temperament and character in preschoolers.

\section{REFERENCES}

1. Zuckerman M, Cloninger CR. Relationships between Cloninger's, Zuckerman's, Eysenck's dimensions of personality. Pers Individ Dif 1996; 21:283-285.

2. Cloninger CR. Completing the Psychobiological Architecture of Human Personality Development: Temperament, Character, and Coherence. In: Staudinger UM, Lindenberger UER, Editors. Understanding 
Human Development: Dialogues with Lifespan Psychology. London: Kluwer Academic Publishers, 2003, p.159-182.

3. Staudinger UM, Lindenberger U. Understanding Human Development: Dialogues with Lifespan Psychology. London: Kluwer Academic Publishers; 2003.

4. Cervone D. The architecture of personality. Psychol Rev 2004;111:183204.

5. Cervone D. Personality architecture: within-person structures and processes. Annu Rev Psychol 2005; 56:423-452.

6. Cloninger CR. Feeling Good: The Science of Well-Being. New York: Oxford University Press; 2004.

7. Cloninger CR. The psychobiological theory of temperament and character: comment on Farmer and Goldberg (2008). Psychol Assess 2008; 20:292-299.

8. Cloninger CR. A practical way to diagnose personality disorder: a proposal. J Pers Disord 2000;14:99-108.

9. Cloninger CR. Character strengths and virtues: a handbook and classification. Am J Psychiatry 2005;162:820-821.

10. Cloninger CR. A systematic method for clinical description and classification of personality variants. Arch Gen Psychiatry 1987;44:573-588.

11. Paris J. Neurobiological dimensional models of personality: a review of the models of Cloninger, Depue, and Siever. J Pers Disord 2005;19:156170 .

12. Lowe JR. Widiger TA. Clinicians' judgments of clinical utility: a comparison of the DSM-IV with dimensional models of general personality functioning. J Pers Disord 2009;23:211-229.

13. Cloninger CR, Zohar AH, Cloninger KM. Promotion of well-being in person-centered mental health care. Focus 2010;8:165-179.

14. Schermelleh-Engel K, Moosbrugger $\mathrm{H}$, Müller $\mathrm{H}$. Evaluating the fit of structural equation models: test of significance and descriptive goodness-of-fit measures. Method Psychol Res Online 2003;8:23-74.

15. Goldsmith HH, Campos JJ. Fundamental Issues in the Study of Early Temperament: The Denver Twin Temperament Study. In: Lamb ME, Brown AL, Rogoff B, Editors. Advances in Developmental Psychology (Vol 4). Hillsdale, NJ: Erlbaum, 1986, p.231-283.

16. Kagan J, Reznick JS, Ckarke C, Snidman N, Garcia-Coll C. Behavioral inhibition to the unfamiliar. Child Dev 1984;55:2212-2225.

17. Pitzer M, Esser G, Schimdt MH, Laucht M. Temperament predictors of externalizing problems among boys and girls: a longitudinal study in a high-risk sample from ages 3 months to 15 boys. Eur Arch Psychiatry Clin Neurosci 2009;259:445-458.

18. Thomas A, Chess S. Temperament and Development. New York: Brunner/Mazel; 1977.

19. Canals J, Hernández-Martínez C, Fernández-Ballart JD. Relationships between early behavioural characteristics and temperament at 6 years. Infant Behav Dev 2011;34:152-160.

20. Degnan KA, Hane AA, Henderson HA, Moas OL, Reeb-Sutherland BC, Fox NA. Longitudinal stability of temperamental exuberance and social-emotional outcomes in early childhood. Dev Psychol 2011;47: 765-780.

21. Neppl TK, Donnellan MB, Scaramella LV, Widaman KF, Spilman SK, Ontai LL, et al. Differential stability of temperament and personality from toddlerhood to middle childhood. J Res Pers 2010;44:386-396.

22. Rubin KH, Burgess KB, Dwyer KM, Hastings PD. Predicting preschoolers' externalizing behavior from toddler temperament, conflict, and maternal negativity. Dev Psychol 2003; 39:164-176.

23. Lindhout IE, Markus MT, Hoogendijk TH, Boer F. Temperament and parental child rearing style unique contributions to clinical anxiety disorders in childhood. Eur Child Adolesc Psychiatry 2009;18:439-446.

24. Keltikangas-Jarvinen L, Raikkonen K, Ekelund J, Peltonen L. Nature and nurture in novelty seeking. Mol Psychiatry 2004;9:308-311.

25. Keltikangas-Jarvinen L, Jokela M. Nature and Nurture in Personality. Focus. J Lifelong Learn Psychiatry 2010;8:180-186.

26. Gillespie NA, Cloninger CR, Heath AC, Martin NG. The genetic and environmental relationship between Cloninger's dimensions of tem- perament and character. Pers Individ Dif 2003;35:1931-1946.

27. Cicchetti D, Rogosch FA. Equifinality and multifinality in developmental psychopatology. Dev Psychopathol 1996;8:597-600.

28. Cloninger CR, Svrakic NM, Svrakic DM. Role of personality self-organization in development of mental order and disorder. Dev Psychopathol 1997;9:881-906.

29. Cho SC, Kim JW, Kim BN, Lee JH, Kim EH. Biogenetic temperament and character profiles and attention deficit hyperactivity disorder symptoms in Korean adolescents with problematic Internet use. Cyberpsychol Behav 2008;11:735-737.

30. Shin YC, Lim SW, Choi SW, Kim SW, Grant JE. Comparison of temperament and character between early- and late-onset Korean male pathological gamblers. J Gambl Stud 2009;25:447-453.

31. Asch M, Cortese S, Perez Diaz F, Pelissolo A, Aubron V, Orejarena S, et al. Psychometric properties of a French version of the junior temperament and character inventory. Eur Child Adolesc Psychiatry 2009;18: 144-153.

32. Olvera RL, Fonseca M, Caetano SC, Hatch JP, Hunter K, Nicoletti M, et al. Assessment of personality dimensions in children and adolescent with bipolar disorder using the Junior Temperament and Character Inventory. J Child Adolesc Psychopharmacol 2009;19:13-21.

33. Cho SC, Kim BN, Kim JW, Rohde LA, Hwang JW, Chungh DS, et al. Full syndrome and subthreshold attentiondeficit/hyperactivity disorder in a Korean community sample: comorbidity and temperament findings. Eur Child Adolesc Psychiatry 2009;18:447-457.

34. Luby JL, Svrakic DM, McCallum K, Przybeck TR, Cloninger CR. The Junior Temperament and Character Inventory: preliminary validation of a child self-report measure. Psychol Rep 1999;84:1127-1138.

35. Cho SC, Jung SW, Kim BN, Hwang JW, Shin MS, Kim JW, et al.Temperament and character among Korean children and adolescents with anxiety disorders. Eur Child Adolesc Psychiatry 2009;18:60-64.

36. Costantino JN, Cloninger CR, Clarke AR, Hashemi B, Przybeck T. Application of seven-factor model of personality to early childhood. Psychiatry Res 2002;109:229-243.

37. Cloninger CR, Svrakic DM. Personality Disorders. In: Sadock BJ, Sadock VA, Ruiz P, Editors. Kaplan and Sadock's Comprehensive Textbook of Psychiatry. New York: Lippincott Williams \& Wilkins, 2009, p.2197-2240.

38. Cloninger CR, Zohar AH. Personality and the perception of health and happiness. J Affect Disord 2011;128:24-32.

39. Pukrop R, Syeinbring I, Gentil I, Schulte C, Larstone R, Livesley JW. Clinical validity of the "Dimensional Assessment of Personality Pathology (DAPP)" for psychiatric patients with and without a personality disorder diagnosis. J Pers Disord 2009;23:572-586.

40. de la Rie SM, Duijsens IJ, Cloninger CR. Temperament, character, and personality disorders. J Pers Disord 1998;12:362-372.

41. Beaton D, Bombardier C, Guilleman F. Recommendations for the Cross-Cultural Adaptation of Health Status Measures. American Academy of Orthopaedic Surgeons. Rosemont, Illinois: Institute for Work and Health; 1998.

42. Beaton DE, Bombardier C, Guilleman F, Ferraz MB. Guidelines for the process of cross-cultural adaptation of self-report measures. Spine ( $\mathrm{Ph}$ ila Pa 1976) 2000;25:3186-3191.

43. Axia G. Questionari Italiani del Temperamento. Trento: Edizioni Erikson; 2002.

44. Arbuckle JL. Amos (Version 7.0) [Computer Program]. Chicago: SPSS; 2006.

45. Byrne BM. Structural Equation Modeling with AMOS. Mahwah: Lawrence Erlbaum Associates; 2001.

46. Kline RB. Principles and Practice of Structural Equation Modeling (2nd Edition). New York: The Guilford Press; 2005.

47. Hu L, Bentler PM. Cutoff criteria for fit indexes in covariance structure analysis: Conventional criteria versus new alternatives. Struct Equ Modeling 1999;6:1-55.

48. Schermelleh-Engel K, Moosbrugger H, Müller H. Evaluating the fit of 
structural equation models: Tests of significance and descriptive goodness-of-fit measures. Method Psychol Res Online 2003;8:23-74.

49. Schönemann PH. A generalized solution of the orthogonal procrustes problem. Psychometrika 1966;31:1-10.

50. Schumacker RE, Beyerlein ST. Confirmatory factor analysis with different correlation types and estimation methods. Struct Equ Modeling 2000;7:629-636.

51. Barrett P. Factor comparison: an examination of three methods. Pers Individ Dif 1986;7:327-340.

52. Cattell RB, Vogelmann S. A comprehensive trial of the scree and KG criteria for determining the number of factors. Multivar Behav Res 1977;12:289-325.

53. Thurstone LL. Multiple-Factor Analysis: A Development and Expansion of the Vectors of Mind. Chicago: University of Chicago Press; 1947.

54. Cloninger CR. A unified biosocial theory of personality and its role in the development of anxiety states. Psychiatr Dev1986;4:167-226.
55. Cloninger CR, Przybeck TR, Svrakic DM. The Tridimensional Personality Questionnaire: U.S. normative data. Psychol Rep 1991;69:10471057.

56. Cloninger CR, Svrakic DM, Przybeck TR. A psychobiological model of temperament and character. Arch Gen Psychiatry 1993;50:975-990.

57. Browne MW, Cudeck R. Alternative Ways of Assessing Model Fit. In: Bollen KA, Long JS, Editors. Testing Structural Equation Models. Beverly Hills, CA: Sage Publications, 1993, p.136-162.

58. Else-Quest NM, Hyde JS, Goldsmith HH, Van Hulle CA. Gender differences in temperament: a meta-analysis. Psychol Bull 2006;132:33-72.

59. Werner EE. Protective Factors and Individual Resilience. In: Meisels SJ, Shonkoff M, Editors. Handbook of Early Intervention. New York: Cambridge University Press, 1990, p.97-116.

60. Eisenberg N, Fabes RA, Bernzweig J, Karbon M, Poulin R, Hanish L. The relations of emotionality and regulation to preschoolers' social skills and sociometric status. Child Dev 1993;64:1418-1438. 